\title{
ATRAVESSANDO FRONTEIRAS: A DIMENSÃO VIVIDA DA DESTERRITORIALIZAÇÃO DE BRASILEIROS EM PORTUGAL E ESTADOS UNIDOS DA AMÉRICA
}

\author{
Adélia Verônica da Silva \\ Instituto de Geografia e Ordenamento do Território da Universidade de Lisboa, Portugal. \\ adeliasilva@campus.ul.pt
}

\begin{abstract}
RESUMO
Inserido em uma perspectiva de análise do fenômeno migratório que, além dos motivos econômicos como fatores de atração e repulsão de fluxos migratórios, privilegia outras dimensões, no presente artigo buscou-se abordar especificamente o processo de construção do projeto de mobilidade internacional de imigrantes brasileiros para as cidades de Lisboa-Portugal e Los Angeles-EUA. Foram realizadas entrevistas semi-estruturadas com 32 imigrantes brasileiros. Para orientar a interpretação da migração internacional foi utilizada uma abordagem territorial/espacial que possibilitasse integrar, simultaneamente, as dimensões materiais e simbólicas objetivas e subjetivas do processo de migração enquanto um processo inicialmente de desterritorialização, compreendida enquanto um processo de desenraizamento original iniciado pelo movimento migratório, e que se dá, em termos existenciais, pela alteração da territorialidade consolidada dos sujeitos, ou seja, de atravessar as fronteiras dos lugares vividos. Esta abordagem busca ultrapassar os limites do nacionalismo metodológico na compreensão dos processos de mobilidade internacional de brasileiros.
\end{abstract}

Palavras-chave: Imigração Internacional. Desterritorialização. Lugares Vividos

\section{CROSSING BORDERS: THE LIVING DIMENSION OF THE DETERRITORIALIZATION OF BRAZILIANS IN PORTUGAL AND THE UNITED STATES OF AMERICA}

\begin{abstract}
ABCSTRAT
Inserting in a perspective of analysis of the migratory phenomenon that, in addition to economic reasons as factors of attraction and repulsion of migratory flows, privileges other dimensions, in the present article sought to specifically approached the construction process of the project of international mobility of Brazilian immigrants to the cities of Lisbon-Portugal and Los Angeles-USA. Semi-structured interviews were conducted with 32 Brazilian immigrants in order to guide the interpretation of international migration, a territorial / spatial approach was used to simultaneously integrate the objective and subjective material and symbolic dimensions of the migration process as a process of initially deterritorialization, that is, of crossing the borders of the lived places. Deterritorialization is understood as an "original uprooting process initiated by the migratory movement, which occurs in existential terms by altering the subjects' consolidated territoriality. This approach seeks to push the boundaries of methodological nationalism in understanding the international mobility processes of Brazilians.
\end{abstract}

Keywords: International Immigration. Desterritorialization. Living Places.

\section{INTRODUÇÃO}

$\mathrm{Na}$ busca por compreender os fluxos e deslocamentos humanos contemporâneos é relevante refletir sobre os contextos espaciais nos quais as experiências de mobilidade são vivenciadas. Todavia, limitar as investigações ao dueto sociedade de origem e sociedade de destino, muito comumente abordado nos trabalhos sobre migração e estruturados a partir dos limites geográficos dos estados-

Caminhos de Geografia $\quad$ Uberlândia $\quad$ v. 20, n. $72 \quad$ Dez/2019 $\quad$ p. 386-401 Página 386


nação - nesse caso Brasil/Estados Unidos da América e Brasil/Portugal, acaba por restringir as análises para uma compreensão dos deslocamentos de brasileiros na atualidade do campo de estudos da Geografia das Migrações. Assim, a proposta deste artigo é abordar as mobilidades humanas no sentido lato - ou seja, espaciais, sociais e físicas; de maneira a compreender as múltiplas escalas nos deslocamentos dos sujeitos, o que implica, por sua vez, em refletir sobre a desterritorialização na mobilidade em uma perspectiva que analisa simultaneamente a dimensão territorial e a existencial (MARANDOLA JUNIOR e DAL GALLO 2010; GLICK SCHILLER e SALAZAR, 2013). Múltiplas escalas, cabe ressaltar, devem ser compreendidas como mobilidades que transpõem as relações entre fronteiras geográficas e abarcam as relações socioeconômicas numa perspectiva existencial.

Não é novidade que nos últimos anos têm surgido alterações nas abordagens clássicas explicativas das migrações, de cunho estruturalistas. Nesse contexto, algumas investigações sobre mobilidades têm centrado suas análises nos elementos simbólicos do processo migratório e na identidade dos sujeitos (MARTINS JUNIOR e DIAS, 2013; TOGNI, 2015). Ao mesmo tempo, a dimensão territorial das migrações tem recebido destaque nos estudos sobre mobilidades, tanto em termos dos estudos de espaços e lugares específicos quanto dos territórios migrantes, diante do fenômeno migratório (BRAGA, 2011; SAQUET, 2007). Todavia, conforme ressaltam Marandola Junior e Dal Gallo (2010), grande parte desta produção teórica focaliza o tema da mobilidade pelo viés sociocultural dos grupos e de suas práticas, não abordando questões propriamente existenciais da mobilidade internacional. É no campo da Geografia que, segundo os autores, tem florescido a possibilidade dessas abordagens serem conciliadas para uma melhor compreensão sobre os processos de territorialização e desterritorialização num aspecto existencial.

As análises de O'Reily e Benson (2009), assim como as de Glick Schiller e Salazar (2013) devem ser acrescentadas nesse debate porque ressaltam a necessidade de investigação dos projetos migratórios sob diferentes perspectivas, nas quais os pesquisadores possam analisar o papel dos Estados-Nação e a preponderância das identidades nacionais na formação da experiência dos sujeitos em deslocamento, sem, todavia, limitar o seu estudo ao parâmetro de Estado-Nação. O nacionalismo metodológico, ao assumir os países como unidades naturais de análise, a partir da naturalização de um "regime global de Estados Nação", confere um papel central nos estudos sobre mobilidades, equacionando a noção de sociedade com os interesses do Estado-Nação e transformando, assim, os sujeitos e as trajetórias em "comunidades" (TOGNI, 2015). Sob essa mesma perspectiva, as diferenças de poder globais, nacionais e regionais exercem um papel determinante nos imaginários sobre a mobilidade, nas condições materiais para sua concretização e, por conseguinte, nas experiências e agência dos sujeitos (GLICK SCHILLER e SALAZAR, 2013). No âmbito da teoria social, as fronteiras têm sido compreendidas de maneira polissêmica, com visões que vão de uma compreensão substantiva na definição de áreas geográficas, até aquelas que se expressam nas construções imaginárias, como "aspectos significativos da experiência humana" (MILLER E STEFFEN, 1977 apud ALMEIDA, 2002, p. 56). Esta é uma concepção de fronteira que ultrapassa a dimensão espacial e política adotada na presente investigação. Sob essa perspectiva, a noção de fronteira é utilizada como recurso heurístico, primeiramente porque a fronteira como dimensão política e territorial expressa os diferentes deslocamentos dos sujeitos da pesquisa entre: Brasil - Portugal; Brasil - Estados Unidos da América. E em segundo lugar, porque, ao analisar as trajetórias dos sujeitos migrantes, constatou-se que a fronteira ocupava um lugar importante em suas experiências. Ao longo da realização do trabalho de campo, foi identificado que, para os sujeitos entrevistados, os deslocamentos entre fronteiras internacionais representavam um encontro de mobilidades diversas, que extrapolavam a dimensão geográfica, ou seja, mobilidade social, física, econômica, residencial e imaginária (GRAW e SCHIELKE, 2012).

Contudo, é importante ressaltar que as pessoas habitam e se movimentam em contextos urbanos com ofertas específicas. Assim, mais que os países de acolhimento e de origem, são as cidades de destino que interferem mais significativamente em seus percursos de vida (CACHADO, 2009). Neste aspecto, a escolha das cidades de Lisboa e Los Angeles surgiu da busca em compreender a diversidade das experiências de mobilidade de "brasileiros" em duas localidades distintas em relação aos sistemas políticos, económicos e sociais. Essa escolha foi, paulatinamente, se configurando como uma estratégia plausível de análise das trajetórias construídas dentro de campos sociais transnacionais, que mesclam a mobilidade territorial com as mobilidades residencial, social e urbana dos sujeitos. As razões de escolha de Lisboa e Los Angeles também se justificam pelo fato de que ambas as cidades estão localizadas em países de destino com grande relevância para o quadro da imigração brasileira. Todavia, enquanto em Lisboa a comunidade brasileira é a mais numerosa, em

$\begin{array}{llllll}\text { Caminhos de Geografia } \quad \text { Uberlândia } & \text { v. 20, n. } 72 & \text { Dez/2019 } & \text { p. 386-401 } & \text { Página } 387\end{array}$


Los Angeles ela é ainda reduzida e as investigações sobre essa comunidade ainda são escassas. Investigar as trajetórias dos imigrantes brasileiros nesses espaços permitiu refletir acerca dos significados das experiências humanas da migração enquanto experiências individuais, vividas cotidianamente por cada um desses brasileiros deslocados (MARANDOLA JUNIOR e DALGALLO, 2010).

Assim, na busca de compreender as trajetórias de trinta e dois imigrantes brasileiros entre fronteiras internacionais, buscou-se analisar, de maneira conjugada, o plano histórico-temporal, espacial, social e simbólico dos deslocamentos realizados. Os resultados aqui apresentados são oriundos da investigação intitulada Leitura Etnogeográfica de Espaços Vividos de Imigrantes Brasileiros em Lisboa e Los Angeles (SILVA, 2019), que teve como objetivo conhecer e analisar os lugares vividos por um grupo de brasileiros em sua trajetória migrante, de maneira a identificar as implicações territoriais e existenciais presentes na (re)construção do seu habitar. Ao todo, foram entrevistados 32 imigrantes, sendo 16 na cidade de Lisboa e 16 na cidade de Los Angeles. Para a constituição da amostra, foi utilizada a técnica denominada "snowball sampling", usualmente traduzida como "bola de neve". Para análise das representações construídas pelos imigrantes sobre as mobilidades socioespaciais vivenciadas, suas escalas e suas relações, foi utilizado como procedimento técnico a entrevista em profundidade que, a partir de um roteiro semiestruturado, se configurou como uma estratégia metodológica para compreensão sobre as experiências e as trajetórias de mobilidade desses sujeitos, assim como sobre os sentidos de melhoria de vida e/ou mudança de vida e os significados dos deslocamentos entre fronteiras internacionais. $\mathrm{Na}$ análise dos dados, foram utilizados os procedimentos técnicos do Método de Análise de Conteúdo de Bardin (1997).

Em sua organização, o presente artigo encontra-se disposto em duas partes. Inicialmente, analizouse o papel do imaginário das representações e das redes sociais como elementos agenciadores e propulsores do projeto de desterritorialização desses sujeitos. Na sequência, a partir das noções de projetos e campos de possibilidades, são descritos os trajetos e trajetórias socioespaciais transnacionais desses brasileiros, enquanto expressão de um quadro sócio histórico, mas que integra singularidades e peculiaridades que possibilitam avançar em relação ao viés racionalista que marca este campo de investigação.

\section{O PROCESSO INICIAL DA DESTERRITORIALIZAÇÃO}

As diferentes correntes teóricas buscam compreender o fenômeno da mobilidade humana a partir de diversas perspectivas de análise. Dentre elas, as teorias de cunho economicista, que privilegiam a relação existente entre migração e desenvolvimento econômico (MASSEY, 1988); as teorias dos fatores de atração e repulsão, que analisam o fenômeno migratório enquanto um processo baseado em duas dinâmicas: push (fatores/áreas de expulsão), na qual as condições do país de origem obrigam as pessoas a emigrarem; e pull (fatores/áreas de atração), na qual os países de destino atraem os imigrantes em busca de prosperidade (LEE, 1966) . Outras teorias, por sua vez, analisam as migrações como um processo de construção de redes sociais, onde os imigrantes encontram estratégias para viverem ligados a dois locais concomitantemente (PORTES, 1995).

No caso específico da imigração brasileira internacional, diversos estudos têm destacado o papel que as crises econômicas e as redes sociais exercem sobre este fenômeno (MARGOLIS, 2001; MARTES, 2001; SALES, 2001; MACHADO, 2009; SIQUEIRA et al, 2017). São reflexões que, em comum, ressaltam os problemas econômicos que surgiram no Brasil, principalmente nos fins da década de 1980, como fatores que impulsionarem o desejo de milhares de brasileiros de saírem do país e que, associados à atratividade de alguns países europeus e dos EUA no cenário socioeconômico mundial, tornam-se significativos para uma compreensão da emigração brasileira.

Ainda nesse aspecto, Schörner (2010) destaca que uma parte significativa dos estudos sobre migrações tende a supervalorizar os fatores econômicos em suas análises, menosprezando o papel dos próprios migrantes enquanto agentes envolvidos nesse processo. Sob essa perspectiva é que consideramos que as experiências de mobilidade dos sujeitos imigrantes seriam incompreensíveis se abordadas exclusivamente por meio das dimensões econômicas e laborais nas sociedades de destino. Assim, de maneira a ampliar a compreensão sobre a imigração para além dos fatores de ordem econômica que a ela são associados, o propósito no presente artigo é privilegiar o desenvolvimento de uma abordagem holística na análise sobre o processo de desterritorialização envolvido no ato desses sujeitos de migrarem, considerando que as teorias sobre as migrações internacionais, marcadas por um nacionalismo metodológico e por concepções isomórficas entre

$\begin{array}{llllll}\text { Caminhos de Geografia } & \text { Uberlândia } & \text { v. 20, n. } 72 & \text { Dez/2019 } & \text { p. 386-401 Página } 388\end{array}$


território, cultura e sociedade, apresentam limitações para uma compreensão das trajetórias e dos trajetos desses migrantes (TOGNI, 2015).

Para tal, assume-se definir o espaço enquanto categoria de entendimento da realidade social dos imigrantes brasileiros, considerando o território em sua concepção holística. Ou seja, território enquanto cenário de vida, de uma realidade dinâmica, espaço de substrato material das sociedades e suporte de memórias, relações sociais, agenciamentos, representações e identidades. Territorialidade é entendida, portanto, como um comportamento humano espacial, ou seja, constituída por um conjunto de relações que se originam de um sistema tridimensional sociedade-espaço-tempo, sendo a "soma" das relações mantidas por um sujeito com o seu meio. Assim, mais que uma simples relação homem-território, a noção de territorialidade vai muito além da demarcação de parcelas individuais, expressando a relação social entre os homens (RAFFESTIN, 1993).

Enfim, interessa destacar que analisar o movimento do imigrante brasileiro, na perspectiva do território e da territorialidade, permite apreender a destruição e a criação de territórios no e pelo movimento - num jogo dialógico entre desterritorialização e reterritorialização ontológico do ser social. Isso porque a mobilidade internacional pressupõe, em primeiro lugar, uma mudança de território para os sujeitos, ou seja, a saída do lugar - habitual/familiar e a chegada ao lugar de destino, nem sempre familiar. Assim, considerando a desterritorialização na migração como o movimento pelo qual o sujeito abandona o território, "a operação da linha de fuga"; assim como a reterritorialização como o movimento de construção do território (HAESBAERT, 2004), enquanto um estudo sobre mobilidades transnacionais, busca-se compreender a realidade que envolve os sujeitos sociais que migram, compreendendo o migrante na sua condição de agente. Sob essa lógica, as relações individuais, as estratégias, os sonhos, os desejos e as representações dos migrantes passaram a ser considerados, também, como condicionantes do processo migratório (HALL, 2004).

Além disso, tendo como apoio os trabalhos de Cresswell (2006) sobre o significado da mobilidade e suas possibilidades de análises, reconhece-se a produção da mobilidade como bifacial: uma face corporal e outra social. Dissociando a ideia da mobilidade como mero movimento, Cresswell afasta-se de uma metáfora ampla de mobilidade - de capitais, mobilidade social, etc., para enfatizar a realizada por pessoas e por grupos. Sob essa concepção, deslocamento ou movimento constitui um processo que leva corpos de um ponto para outro; mas em uma concepção mais ampla, de natureza social, que envolve estruturas, meios, cultura e significados (CRESSWELL, 2006).

Dessa forma, é possível reconhecer a mobilidade humana como uma experiência incorporada de forma irredutível. Assim, ir de um lugar a outro pode tornar-se sinónimo de liberdade, de criatividade, de realização com a própria vida, entre muitos outros significados. Todavia, esse movimento de ir de um lugar a outro não ocorre no espaço abstrato - sem conteúdo, aparentemente natural e desprovido de significado, história e ideologia. Pelo contrário, realiza-se entre locais imbuídos de sentidos e poderes. Portanto, analisar a territorialidade dos migrantes brasileiros torna-se uma forma de aproximação das vivências destes sujeitos numa perspectiva geográfica do ser social, que opera estruturalmente em campos sociais que ultrapassam as fronteiras nacionais (MAZZUCATO, 2004).

Enfim, compreender o processo da migração desses sujeitos enquanto um processo de desterritorialização, exigiu problematizar e analisar desde a subjetividades dos impulsos desterritorializantes à corporificação das mobilidades transnacionais desses brasileiros. Cabe acrescentar, ainda, que a busca de compreensão de como essas experiências de deslocamento espacial são vividas pelos migrantes - desde o contexto cultural prévio no qual são interpretadas, suas estratégias e capacidade criativa, até às transformações vivenciadas por esses sujeitos, exigiu um diálogo com o conceito de agência (KING, 2012). Sob esse ponto de vista, o agente individual constitui a única entidade capaz de conferir sentido às ações sociais (WEBER,2004). Ou seja, analisar a desterritorialização internacional desses brasileiros exigiu refletir sobre os sentidos subjetivamente atribuídos a migração, e, ainda, considerar que as ações desses sujeitos são pautadas em motivações materiais e simbólicas dentro de um repertório acumulado em suas trajetórias e experiências. O pensamento Weberiano, dessa forma, apresenta-se como uma contribuição importante para as investigações em mobilidade, tanto pela superação das tradicionais categorias macroestruturais que marcam este campo de investigações, quanto por possibilitar revelar os sentidos e as conexões presentes nas ações dos sujeitos transnacionais. Especificamente, em

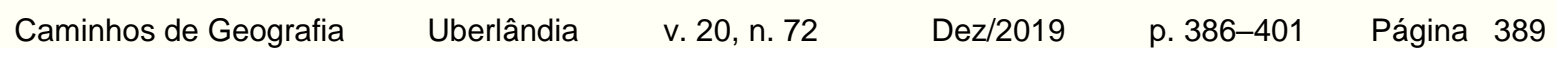


relação ao migrante, essa perspectiva destaca o migrante, mas não como um sujeito isolado; mas encontrando-se sempre inserido em um grupo ou em relação com outro sujeito. A partir dessa perspectiva, torna-se possível uma contraposição das narrativas totalizantes que, partindo de modelos hegemónicos económicos e políticos que assumem o migrante como sujeito dos processos económicos globais, terminam por menosprezar e desconsiderar as condições reais de existência dos sujeitos nas quais as suas ações e as suas decisões são realizadas.

No conjunto das narrativas construídas pelos imigrantes brasileiros, um dos argumentos utilizados recorrentemente pelos entrevistados para justificarem o processo da emigração era a possibilidade de acesso a uma vida melhor fora do Brasil (SANTOS, 2009). A significativa frequência de expressões como "buscar uma vida melhor", "mudar a minha vida", "ter uma vida melhor", dentre outras que emergiram por ocasião das entrevistas conduziu a reconhecer a lógica melhoria de vida como uma categoria tópica para compreensão das motivações desses sujeitos para a mobilidade geográfica. Acrescente-se, ainda, que esse sentido atribuído à migração pareceu um caminho promissor para ampliar a compreensão sobre esse fenômeno, uma vez que, sem negar a importância da dimensão socioeconômica - fatores push/pull como pano de fundo para análise da imigração brasileira, possibilitava extrapolar uma visão dos movimentos migratórios como um fenômeno unidirecional. Os fragmentos das entrevistas, por sua vez, elucidam que essa ideia de "melhoria de vida", recorrente nas narrativas dos migrantes brasileiros, não se refere apenas ao caráter economicista da mobilidade, como destacado a seguir:

$\mathrm{Na}$ época que decidi vir para cá, já estava um pouco insatisfeita com o ritmo de vida que tinha no Brasil. Trabalhava muito, vivia pouco. Estive em Miami de férias e adorei. Voltei para o Brasil com a intenção de ir mora lá. Pedi demissão do meu emprego e ir conhecer outras pessoas, culturas e coisas, viver outras coisas, sabe? Sair do Brasil. Sempre tive essa vontade de mudar de vida, e no Brasil eu sentia que isso não era possível. Vivia num mundo que era tudo igual. Tinha um bom emprego, uma casa, mas queria mais. Queria ter outras coisas, outras experiências. Queria me desafiar, melhorar a minha vida, mudar de vida. Não tinha nada a perder. Falava um pouco de inglês, por isso pensei que conseguiria um emprego, não igual ao que eu tinha no Brasil, mas ganharia igual ou um pouco melhor e trabalharia menos. Então, resolvi que iria ver como é viver em um outro país (Regina, imigrante brasileira em Los Angeles).

Eu tinha um amigo que veio para Londres, e continuamos a manter contato pela internet. Nunca tinha pensado em sair do Brasil. O meu amigo começou a me falar como era a vida lá e como Brasil era outro nessa altura, eu fiquei a sonhar com aquilo. Pensava como Londres era cosmopolita, cheio de gente de outras nacionalidades, como você era influenciado por essas pessoas, como era legal a vida lá. Me parecia que era uma vida muito mais flexível para as estruturas rígidas da vida que a gente tem no Brasil. Eu via que ele tinha uma vida flexível, se não gostava de um emprego, saia e amanhã arrumava outro. Eu me sentia muito preso as estruturas aquela altura. Então achei aquilo mais interessante. Tinha aquilo que os brasileiros almejam na minha opinião, ter a flexibilidade das viagens, o alcance e... outra... um senso de liberdade muito grande. Ter minha vida particular, na altura eu pensava em viver sozinho e tudo que eu via era muito caro para mim, e aqui (na Europa) parecia que tudo funciona. Então eu tive aquela curiosidade imensa que me levou a mudar, queria mudar a minha vida para melhor (Walter, imigrante brasileiro em Lisboa).

Torna-se importante ressaltar que praticamente todas as formas da migração encontram-se relacionadas às aspirações dos sujeitos migrantes por uma "vida melhor". Entretanto, as motivações subjacentes às decisões de migrar assumem representações distintas para os diferentes sujeitos. Nesse aspecto, Durham (1973) reconhece que melhorar de vida é o modo que os brasileiros dão sentido, num primeiro momento, ao projeto de se deslocarem entre fronteiras nacionais $e$ internacionais (TOGNI, 2015).

Apesar dos termos melhoria/mudar de vida apresentarem significados diversos nas narrativas dos entrevistados, foi identificado que para estes migrantes o sentido de se mover para outro país encontra-se associado à representação de usufruir oportunidades sociais e econômicas não disponíveis localmente, ao mesmo tempo em que se associa a um desejo em conhecer novas culturas. Nesse sentido, é importante ressaltar o papel dos imaginários socialmente compartilhados na sociedade brasileira, e cada vez mais presentes no mundo contemporâneo, de extrema valorização, ou ainda, de uma romantização das experiências de cruzar fronteiras. Nesse contexto,

Caminhos de Geografia Uberlândia $\quad$ v. 20, n. $72 \quad$ Dez/2019 $\quad$ p. 386-401 Página 390


os movimentos migratórios são percebidos como movimentos desejáveis (SALAZAR e JAYARAM, 2016) e, até mesmo, como caminhos normativos para a plena realização do potencial humano.

$\mathrm{Na}$ busca por uma melhor compreensão sobre a relação existente entre o desejo de imigrar dos sujeitos entrevistados e a representação compartilhada por todos eles de que a migração permitiria alcançar uma "vida melhor", que não era possível no Brasil, tornou-se necessário aprofundar analiticamente a questão das racionalidades econômicas da globalização que encorajam a emigração. Também é imprescindível um aprofundamento na análise das dinâmicas culturais que modelam relações humanas e políticas, de maneira que possamos compreender, a partir dos contextos de origem dos sujeitos imigrantes, as lógicas culturais que tornam esses deslocamentos pensáveis, praticáveis e desejáveis, e que se encontram vinculadas a processos de acumulação de capital (MACIEL, 2012).

Sob essa perspectiva, foi possível compreender que os discursos desses imigrantes brasileiros revelam uma narrativa de fuga: uma fuga de lugares que, para eles, possuía uma representação negativa da vida antes da migração. Assim, a saída do Brasil representava, antes de tudo, um escape de um lugar onde a "vida boa" não era acessível no território de origem, em todos os sentidos do termo acessibilidade. Sob essa perspectiva, a migração desses sujeitos foi motivada por insatisfações diversas, tanto na esfera econômica, como na esfera social de suas realidades de vidas no Brasil, aliadas ao desejo, ou mesmo, a uma curiosidade de conhecer novas culturas. Nesse contexto, a migração se apresentava como uma estratégia de melhoria de vida, de restabelecimento de um melhor equilíbrio entre as necessidades socialmente definidas e a remuneração do trabalho (SCHÖRNER, 2010), aliada ainda à concretização de um desejo em conhecer um novo país, uma nova cultura.

Portanto, cabe ressaltar que a "vida melhor" desejada pelos imigrantes brasileiros não se refere exclusivamente a uma busca de prosperidade econômica; mas envolve também fenômenos de natureza subjetiva, a exemplo de fuga da violência, desejo de autonomia perante os familiares, imaginário de uma vida moderna (MAPRIL, 2008), dentre outros desejos a serem realizados ao se viver em Portugal e ou nos Estados Unidos da América, permeados pelo trabalho e acesso aos bens de consumo.

Dessa maneira, uma análise das narrativas construídas por esses imigrantes brasileiros sobre as suas vivências migratórias revela a complexidade dos fatores envolvidos e impulsionadores da mobilidade humana, bem como da inconsistência de uma categorização rígida desses fatores (FOUQUET, 2007). Nesse sentido, histórias como as de Ananda e Bernardo - que ansiavam por sair da sua cidade natal em busca de maior autonomia familiar - aliada à vontade de conhecerem outro país; ou a história de Tácio - que após ter o seu estabelecimento comercial assaltado e não conseguir manter o seu negócio, decidiu mudar-se sozinho para Portugal - em comum revelam e explicitam a debilidade de justificativas restritas à dimensão economicista para uma compreensão das representações e motivações subjacentes ao processo de imigração internacional brasileira.

Assim, observar os imaginários desse grupo de brasileiros contribui para refinar a compreensão sobre a tomada de decisão nos processos de mobilidade. Certamente, as matrizes das representações e desejos dos imigrantes brasileiros são plurais e complexos. Porém, é importante ressaltar que, apesar dos imaginários existirem em um nível abstrato, eles se constituem uma parte importante das motivações dos migrantes, visto que os imaginários manifestam como representações comuns das aspirações, esperanças e sonhos.

É neste aspecto que torna-se possível afirmar que a mobilidade entre países despontava no imaginário destes entrevistados como possibilidade para um crescimento, que não se limitando somente a materialidade - acesso a melhores salários, poder de compra, constituição de poupanças, entre outros - ao mesmo tempo abrangia um crescimento simbólico de capital (FOUQUET, 2007). Ou seja, migrar para estes sujeitos assume um sentido mais amplo e subjetivo, que pode ser compreendido como sendo o de envolver em um ciclo de vida significativo (GLICK SCHILLER e SALAZAR, 2013). Em alguns momentos das narrativas dos entrevistados, emergiram termos como a busca por autorrealização, autodesafio ou autodesenvolvimento. Sob essa perspectiva, a migração era representada como uma oportunidade transformativa, de vários modos, permitindo uma fuga de situações de estresse e/ou de um status socioeconômico potencialmente comprometido, ao mesmo tempo em que apresentava possibilidades de fornecer a própria fonte simbólica de capital.

Sob essa perspectiva teórica, a categoria melhoria de vida torna-se uma noção eficaz para compreensão e análises dos deslocamentos entre fronteiras internacionais, a partir de uma lógica que

$\begin{array}{llllll}\text { Caminhos de Geografia } & \text { Uberlândia } & \text { v. 20, n. } 72 & \text { Dez/2019 } & \text { p. 386-401 Página } 391\end{array}$


ressalta aspectos desses deslocamentos que são mais sutis que aqueles exclusivamente econômicos (TOGNI, 2015). Assim, torna-se possível entender que os termos "mudança de vida" e "melhoria de vida", recorrentes nas narrativas dos entrevistados, a despeito de suas formas e contornos diferenciados, apresentam aspectos comuns em suas representações. São narrativas que, apesar de não desprezarem as motivações de ordem econômica para o trabalho em outro lugar, revelam a existência de outros fatores, relacionados a questões de ordem mais privadas, personalizadas e/ou de natureza idiossincrática, que não devem ser ofuscadas por argumentos econômicos coletivos, que são mais facilmente articulados e aceitáveis, conforme destacado por Constable:

As motivações econômicas são, sem dúvida, um importante fator na decisão de se deslocar, mas ao mesmo tempo "uma resposta fácil, uma resposta mais aceitável e até certo ponto uma resposta automática e incompleta que tende a encobrir o que a riqueza etnográfica pode revelar (CONSTABLE, 1999, p. 212 Tradução da autora)

O uso das narrativas como instrumento da presente investigação permitiu compreender a migração como objeto de uma representação relacionada à oportunidade de mudanças. $\mathrm{Na}$ especificidade dos entrevistados, essa representação de "vida melhor" também se encontra associada, por um lado, às elocuções sobre a sociedade brasileira, como a falta de oportunidades, os baixos salários, a violência e a dificuldades de acesso a alguns equipamentos de consumo. Por outro lado, e ao mesmo tempo, expressões como a vontade de conhecer e viver em outro país, o desejo de viver longe da família, a ânsia por "ganhar" o mundo, a busca de autonomia, o cruzar fronteiras, o contato com "o diferente", o sair do lugar e o não pertencimento cultural também vão se misturar nas representações dos sujeitos, como elementos motivadores de sua saída do Brasil.

Nas histórias de mobilidades narradas pelos sujeitos entrevistados é possível identificar que o lugar imaginado por eles era o lugar das realizações de seus desejos e pleno de possibilidades. Tanto os Estados Unidos da América como Portugal foram representados como destinos que ofereciam a oportunidade de acesso a um modo de vida melhor e eram relacionados a privilégios e oportunidades que não são acessíveis a todos os cidadãos (Zamberlam, 2004). Neste contexto que buscou-se compreender as imagens e as concepções construídas por estes sujeitos sobre as cidades - Lisboa ou Los Angeles, de maneira a identificar a concepção do espaço vivido em sua materialidade. Isso porque, nos processos migratórios a imagens sobre o lugar de destino se apresentam, para o imigrante, como uma evocação sonhadora de um cotidiano melhor (DADALTO 2013) em lugares longínquos mapeados no tempo futuro.

Assim, as reflexões de Glick Schiller e Salazar (2013) sobre transnacionalidade e cidades, contribuíram para uma melhor compreensão sobre a construção dos imaginários urbanos na mobilidade. Sob essa perspectiva, compreender as representações dos sujeitos sobre a cidade de destino se tornou relevante para compreender não apenas a cidade enquanto espaço da experiência humana, mas igualmente como espaço de construção de expectativas de futuro, de lugar de trabalho, de sonhos e de elaboração de suas vidas na cotidianidade. As experiências dos sujeitos com a cidade revelaram, ainda, a condição singular de espaço, potencializado do pensar e viver o tempo, das relações humanas em sua pluralidade e polifonia. Investigar as imagens criadas sobre as cidades de destinos possibilitou, assim, reflexões sobre as representações mentais dos sujeitos projetados no tempo e espaço e os sentidos atribuídos para suas mobilidades, conforme destacado nos relatos dos entrevistados.

Eu imaginava uma cidade grande, conhecia já por fotos, vídeos e filmes um pouco. Uma cidade grande, movimentada, interessante, com muitas coisas boas para fazer. Muitas atracões culturais, muitas pessoas diferentes, cosmopolita, pessoas de toda parte do planeta aqui, era o que eu imaginava (Fernanda, imigrante brasileira em Los Angeles).

Sabia que Lisboa era uma cidade antiga, vi algumas fotos dos amigos aqui. Mas como Portugal está na Europa, logo imaginei uma vida moderna com maior facilidades de transporte, trabalho e vida cultural (Adriano, imigrante brasileiro em Lisboa).

É importante destacar que, apesar da decisão de se tornar um migrante ser individual, ela está parcialmente estruturada por imaginários socialmente compartilhados. Neste sentido, identificou-se que tantos os imigrantes brasileiros entrevistados em Lisboa, quanto em Los Angeles, apesar de migrarem para destinos distintos, compartilhavam de representações semelhantes sobre as cidades imaginadas. São representações nas quais as cidades de destino eram concebidas como uma metrópole, desenvolvida, limpa, organizada, segura, bonita, com pessoas educadas e simpáticas.

Caminhos de Geografia $\quad$ Uberlândia $\quad$ v. 20, n. $72 \quad$ Dez/2019 $\quad$ p. 386-401 Página 392


Compreender que os lugares são, simultaneamente, a construção concreta e simbólica do espaço tornou-se um "caminho" para compreender as trajetórias desses imigrantes brasileiros. Torna-se necessário salientar que nem todos os entrevistados tinham imagens sobre as cidades de destino, na medida em que muitas representações foram construídas sobre o país de destino.

\title{
Não sabia nada sobre Los Angeles, apenas sabia que era Estados Unidos, logo, era um país desenvolvido, cheio de oportunidades e facilidades (Bernado imigrante brasileiro em Los Angeles).
}

Sobre Lisboa especificamente não sabia nada, sabia que em Portugal se falava português e era um lugar bom para se viver (Carina, imigrante brasileira em Portugal).

Em comum, essas representações dos lugares de destino revelavam uma valorização e imagem positiva das estruturas das cidades enquanto espaço de convivência humana. Neste aspecto, compreender como é construído o imaginário do lugar de destino pelos brasileiros, significa também compreender a sociedade, a partir das relações entre os sujeitos e destes com o meio. Por esta razão, "a vida social é impossível fora de uma rede, simbólica" (TRINDADE e LAPLANTINE, 1997, p. 9). É por meio desta rede que emerge o imaginário mobilizador e evocador das imagens, que utilizando o simbólico para expressar-se e existir. As reflexões de Trindade e Laplantine (1997) auxiliam essa compreensão sobre o processo do imaginário:

\begin{abstract}
O processo do imaginário constitui-se da relação entre o sujeito e o objeto que percorre desde o real, que aparece ao sujeito figurado em imagens, até a representação possível do real. Esse possível real consiste na potencialidade, no conjunto de todas as condições contidas virtualmente em algo. Nesse sentido, o imaginário não apenas previne situações futuras, como em sua atividade antecipatória orienta-se para um porvir não suspeitado, não previsto. A determinação deste futuro virtual é acometida por uma imaginação transgressora do presente dirigida à consecução de um possível não realizável no presente, mas que pode vir a ser real no futuro" (Idem).
\end{abstract}

Sob essa perspectiva, as imagens não se restringem apenas a acontecimentos objetivos, que despertam a imaginação; são também estímulos que vão muito além do que a visão pode mentalmente capturar. E serão muitas vezes através destes estímulos que, além de uma dimensão visual, o imigrante brasileiro vai construir um espaço imaginado anterior à sua viagem (DE ALBUQUERQUE et al 2017). Evocando e mobilizando informações provenientes dos amigos, familiares, conhecidos e, eventualmente, veiculadas pela mídia, o sujeito vai sucessivamente processando e reprocessando essas informações até transformá-las em espaço imaginado, anteriormente ao seu deslocamento. Nas narrativas a seguir, é possível identificar o papel das redes sociais e da mídia na construção das imagens do lugar de destino:

Não tinha uma ideia muito clara sobre Lisboa, imaginava uma cidade grande moderna. Não sabia muito sobre Portugal, assim em termos de História e Economia. Sabia que estava na Europa. Via meus conhecidos e primos a postarem fotos dos lugares. Cada lugar bonito, diferente daquilo que a gente conhece lá no Brasil. Minha tia me falava que era fácil usar o transporte público aqui, que as pessoas aqui eram calmas e educadas. Assim sempre pensei: que cidade bonita e agradável para se viver (Leandro, imigrante brasileiro em Lisboa).

Sabia onde estava Los Angeles geograficamente, acompanhava uma revista de esporte daqui. Na revista sempre aparecia essa praia de Venice. Também via muitos filmes que passavam aqui, tudo lindo, perfeito para viver. Nos filmes e nas revistas parecia um paraíso para se viver. (Francisco, imigrante brasileiro em Los Angeles).

É possível, portanto, compreender que as representações mentais dos lugares de destinos - sejam cidades ou países, projetadas em um tempo e um espaço futuro atribuíram sentidos aos processos de mobilidades vivenciados pelos sujeitos dessa investigação. Assim, a medida que estes sujeitos imigrantes construíam suas representações mentais, eles imaginavam os destinos Lisboa e Los Angeles não apenas como espaço de experiências humanas, mas fundamentalmente como espaços de realização de suas expectativas positivas de um futuro, estruturadas num dado momento do presente.

Nos processos de mobilidade desse grupo de brasileiros entrevistados, as redes sociais tiveram um papel importante. Assim, para a sua compreensão, torna-se necessário recorrer a dois conceitos semânticos: redes sociais, enquanto abordagem teórica alternativa de análise das migrações

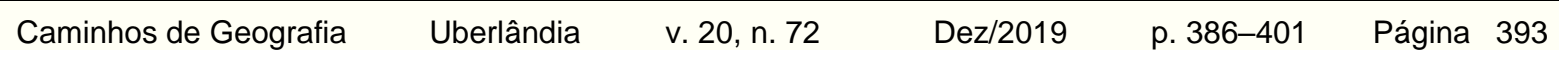


internacionais, que surge como um esforço de construção do trânsito entre as perspectivas estruturalistas e subjetivistas; e redes sociais virtuais, importantes tecnologias que possibilitam examinar e compreender situações de comunicação e conexão e a organização de sociabilidades. $\mathrm{Na}$ atualidade, a reflexão sobre a conexão entre migrantes e não-migrantes no tempo e no espaço através de redes, deve-se considerar não apenas as redes sociais baseadas em laços de amizade e parentesco, mas também, analisar em suas funcionalidades as redes sociais virtuais.

A análise das redes sociais nos estudos migratórios surgiu da necessidade de considerar os processos sociais concretos que possibilitam compreender a dinâmica cultural denominada de desterritorialização. Processos sociais concretos como aqueles que incluem as redes de pessoas que, operando entre as esferas micro e macro, organizam, de fato, o processo da migração. Baily (1985), ao analisar o caso dos italianos na Argentina, refere-se às redes sociais na migração como redes de "contatos pessoais, comunicações e favores entre famílias, amigos e paesani (conterrâneos de um mesmo paese, ou aldeia) em ambas as sociedades, emissora e receptora", que atuam como "fatores fundamentais para determinar quem emigrava, como escolhiam seu destino, onde se estabeleciam, como obtinham trabalho e com quem se relacionavam socialmente" (BAILY, 1985, p. 47). Sob essa perspectiva, as redes sociais podem ser consideradas como o mesonível de análise dos processos de migração. Faist (2000) identifica que as redes sociais típicas envolvidas no local de origem são de amigos e família, enquanto que na área de destino têm sido, cada vez mais, as redes cibernéticas, como blogs, fóruns e outros sites construídos por usuários na internet. Segundo o autor, as relações pessoais constituem canais de transmissão da informação, sendo, portanto, um recurso territorial importante para os migrantes que, inseridos numa rede, podem utilizar desse recurso, que se constitui numa fonte de poder.

Foi no final da década de 1990 que as redes sociais ganharam relevância no âmbito dos estudos sobre imigração brasileira. Diversos investigadores, como Padilla (2006); De Oliveira Assis (2007); e Siqueira (2009), ao estudarem a mobilidade de brasileiros, identificaram que as redes sociais, inicialmente as de amizade e parentesco, colaboravam para a compreensão não apenas dos motivos que levavam os brasileiros a migrarem, mas também das razões da escolha dos locais de migração, da forma como eles se articulavam na chegada ao país receptor, de como os laços sociais ofereciam facilidades e ganhos no deslocamento, dentre outros.

É sob essa perspectiva, analisando as narrativas dos sujeitos entrevistados sobre o planejamento de suas viagens, que é possível compreender os imigrantes enquanto atores sociais, que atuam no interior de suas redes sociais, mobilizando os capitais sociais que Ihes são disponíveis. São relatos que revelam que o projeto da imigração internacional desses sujeitos teve início muito antes deles entrarem em uma aeronave e transporem as fronteiras geográficas dos lugares. Indicam, ainda, que foi necessário um "certo" planejamento e/ou algumas providências que permitissem a esses sujeitos chegarem a Lisboa ou a Los Angeles. E é justamente nesse momento que as redes sociais assumiram um papel importante nos processos de mobilidades desses sujeitos, que, mesmo quando atuaram isoladamente, não o fizeram desconectados de uma rede social, seja física ou virtual (MASSEY et al., 1993; e ZHOU e PORTES 2012).

Eu já queria muito sair do Brasil, quando fiquei desempregado pensei: é agora. Não tenho filhos, vou ganhar o mundo. Fiz contato com um amigo que estava nos Estados Unidos há muito tempo, na Flórida. Ele me disse que para entrar lá de avião era preciso o visto ou cruzar a fronteira do México. Ele só poderia me ajudar se eu já estivesse lá. Então contactei um amigo do meu irmão que estava aqui em Portugal, o Zé. O Zé disse vem para Portugal que não precisa de visto, aqui é tranquilo e você consegue o visto para trabalhar, eu te ajudo, talvez lá onde eu trabalho você consegue trabalhar (Daniel, Imigrante brasileiro em Portugal).

Meu cunhado e minha irmã já estavam aqui nos Estados Unidos. Quando meu cunhado esteve no Brasil, eu disse a ele que queria sair fora de lá... Ele disse: vem pro Estados Unidos, que te ajudo a tirar o visto, e lá você tem casa e trabalho para começar (Edson imigrante brasileiro em Los Angeles).

Meu irmão já estava aqui (LA), então eu disse a ele quando meu namoro acabou, que queria vir para cá... Ele já me convidava sempre. Ele aplicou o pedido de nacionalidade da minha mãe, e ela agora vai aplicar para mim (Kátia imigrante brasileira em Los Angeles).

Eu falei com a minha vizinha que queria vir morar em Portugal quando vi uma reportagem de Lisboa na TV. Ela disse: lembra do Marcelo (outro vizinho)? Ele está

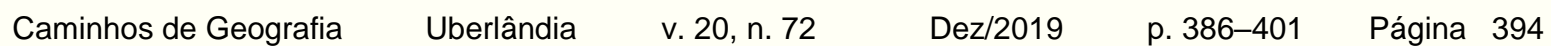


morando lá já há alguns anos. Eu cheguei em casa e procurei o Marcelo no Orkut (naquela época), começamos a falar sobre eu vir para cá, ele me deu muitas dicas do que fazer. Onde comprar a passagem, entrar por Espanha, o seguro de saúde. Cheguei e fui para casa dele, mas depois não funcionou ficar lá (Márcio imigrante brasileiro em Lisboa).

Estudos como o de Padilla (2006) sobre a Imigração brasileira em Portugal, assim como o de De Oliveira Assis (2007) sobre brasileiros em Boston, evidenciam a pertinência das redes sociais para uma compreensão da desterritorialização e reterritorialização brasileira. Segundo as autoras, parte significativa dos brasileiros faz uso das redes sociais desde antes da saída do Brasil até o momento da chegada e da inserção no mercado de trabalho. De igual modo, foi identificado que todos os sujeitos entrevistados $100 \%$ ( $N=32)$ na investigação utilizaram o apoio das redes sociais, em algum momento, para empreenderem o seu projeto migratório. Tanto os brasileiros que migraram para os Estados Unidos da América, quanto os que migraram para Portugal, possuíam um amigo, um parente, um vizinho ou um "contato" que já se encontrava estabelecido nesses países. Da mesma forma, foi verificado que todos os sujeitos entrevistados conectaram em algum momento antes da viagem as redes sociais virtuais - Facebook, Orkut, E-mails, Blogs, etc., seja para acesso a alguma informação sobre o país de destino ou para localizar alguém ou algum meio que poderia ser o "elo de ligação" entre eles e o local de acolhimento. Nos trechos das entrevistas abaixo, os entrevistados reconhecem a relevância das redes sociais para os seus propósitos de mobilidades:

Eu não falava inglês, mas minha irmã falava. Ela sempre me dizia: não se preocupe, nos te ajudamos (ela e o marido). Você, com o tempo, aprende. Como eles estavam aqui já há alguns anos, eu fiquei tranquila, não estaria sozinha em um lugar novo, que não conhecia. Isso me tranquilizava (Angêla, imigrante brasileira em Los Angeles).

O meu amigo ainda não tinha documento, por isso ele não queria escrever a carta convite para mim, tinha medo. Então, perguntei à minha mãe sobre um amigo dela da igreja que estava vivendo em Lisboa, mas ela não sabia como achar ele. Uma amiga me disse: olha no Facebook, acho que ele está em um grupo dos amigos da igreja. Fui lá no Facebook e achei ele, falei com ele e ele escreveu a carta para mim (Ananda, imigrante brasileira em Lisboa).

Tanto no país de origem, quanto no destino, as redes sociais assumiram um papel importante na trajetória desses sujeitos entrevistados, pois foram os familiares, amigos ou conhecidos que os auxiliaram na saída com apoio moral e/ou financeiro; enquanto na chegada, facilitaram a moradia e ajudaram nas primeiras necessidades. Um outro aspecto importante a ser ressaltado, nesse processo, é que os sujeitos desta investigação efetuaram seus deslocamentos entre fronteiras internacionais desacompanhados de outros membros da família nuclear, o que evidencia ainda mais que esses projetos de mobilidade estiveram relacionados a complexas relações de reciprocidade, de ajuda familiar e de amizade, bem como à mobilização de recursos financeiros e/ou simbólicos que permitiram a execução de seus projetos de mobilidade.

Todavia, nesses processos, a ocorrência de parentalidade nas relações sociais foi identificada com maior peso entre os entrevistados que residiam nos Estados Unidos da América do que entre os que residiam em Portugal. Nesse sentido, torna-se importante analisar como a dimensão legal da imigração - que é diferente nos dois países envolvidos no estudo - auxilia para melhor compreensão sobre as redes de reciprocidade construídas entre imigrantes no processo de mobilidade. As redes de relações sociais favorecem as posições que cada sujeito assume no contexto da migração internacional, assim como suas estratégias, na medida em que elas possibilitam eleger destinos, ao mesmo tempo em que as relações de reciprocidade entre os sujeitos envolvidos na mobilidade configuram os trajetos. Segundo Gurak e Caces (1998), as redes sociais, ao servirem de vinculação e transmissão de recursos, podem determinar a escolha do local de destino e, de certa forma, quem são os sujeitos e as famílias do local de origem que migram.

Assim, a utilização da noção de redes e de reciprocidade, numa perspectiva sociológica de longo alcance na mobilidade internacional, também exige considerar a existência de graus de intensidades na vida comunitária, ou seja, mais ou menos trocas, sociabilidades e relações entre as pessoas (BAILY, 1985). Em sua investigação sobre brasileiras em Boston, especificamente sobre as relações de gênero e as redes sociais tecidas no processo migratório, De Oliveira Assis (2007) identificou que as mulheres utilizaram principalmente as redes sociais familiares para empreenderem a suas mobilidades. Considerando que a transposição de fronteiras internacionais envolve riscos e custos, que muitas vezes exigem uma mobilização dos sujeitos e suas relações de reciprocidade, é por meio

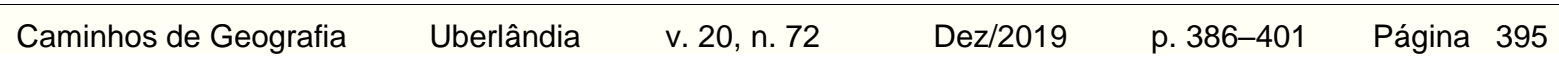


das redes familiares que são obtidos os recursos necessários para a mobilidade. Neste aspecto, foi identificado que, em Los Angeles, uma cidade na qual a dimensão legal da migração é muito mais rígida que em Lisboa, as redes sociais familiares foram acessadas com mais frequência pelos sujeitos da investigação.

Além disso, constatou-se que a existência de contatos pessoais prévios nos lugares de destino representava para estes sujeitos fatores que contribuíram para diminuir as incertezas e os riscos que fazem parte do processo migratório. Como a migração internacional pressupõe a inserção em uma sociedade com costumes, valores e línguas diferentes, foram as redes sociais e cibernéticas que permitiram aos sujeitos 0 acesso às informações e aos caminhos e estratégias que os auxiliaram frente às dificuldades que enfrentaram na mobilidade internacional (TRUZZI, 2008).

Nesse sentido, a presença de relações primárias no local de destino representava para esses sujeitos a tranquilidade destes contatos se tornarem futuros mediadores entre eles e uma provável falta de familiaridade com as estruturas, os espaços, a dinâmica e o funcionamento cotidiano da cidade de destino. Representaram, portanto, contatos, mediadores, pontos de apoio que assumem um papel muito importante para os sujeitos que não dominavam a língua local no início de seus processos de ajustamento a nova vida (DURHAM, 1973), como no caso de alguns brasileiros em Los Angeles. A compreensão da mobilidade desses sujeitos a partir da abordagem das relações sociais como categoria permitiu compreender os papéis desempenhados pelos migrantes junto a suas redes de amigos, parentes e conhecidos e, ainda, nas redes virtuais para a realização de suas mobilidades. Permitiu, assim, compreender as vivências, os comportamentos e as relações individuais ou coletivas que orientaram as trajetórias desses sujeitos. Portanto, a rede social fundada em laços de amizade e familiares e com base na identidade de uma comunidade específica se constituiu uma subcategoria analítica importante para uma melhor compreensão dos processos de mobilidade na atualidade (TRINDADE, 1995).

Contudo, é importante ressaltar que, longe de criar relações fixas, transladadas para os territórios de destino, as redes sociais (virtuais ou não), e suas relações sofrem mudanças, são recriadas e reinventadas, envolvendo negociações entre os seus membros. Por outro lado, é possível observar que, através das redes sociais, se constroem simbolicamente lugares como "Brasil", "Europa" e "Estados Unidos da América".

\section{O PROJETO DE MOBILIDADE TRANSNACIONAL: ENTRE DESEJOS E POSSIBILIDADES}

Como geógrafos das emoções (Da SILVA, 2003), buscou-se na investigação realizada construir um olhar sobre as narrativas do vivido e as práticas de brasileiros com vistas a compreender como esses futuros imigrantes empreenderam seus projetos de mobilidade a partir de seus locais de origem. É preciso entender o projeto como "a conduta organizada para atingir finalidades específicas" (VELHO, 2003, p. 101), que orienta uma antecipação da futura trajetória do sujeito. No delineamento desse projeto, o sujeito utiliza-se da dimensão da memória, de forma a ponderar não apenas a ação do presente, mas ainda as significações impressas das experiências passadas. Assim, ao investigar as representações sobre a mobilidade, os lugares de destino e o papel das redes sociais, o propósito foi compreender como o imaginário desses sujeitos funcionou como agente estruturador, estimulador e catalisador para as suas práticas frente às possibilidades da mobilidade. Ou seja, procurou-se evidenciar como o imaginário, enquanto horizonte de possibilidades, constituiu para estes imigrantes uma força impulsionadora de projetos que os levaram a cruzar fronteiras. Nesse sentido, a possibilidade de realizar uma análise micro das experiências de mobilidades desses imigrantes auxiliou compreender que existem sempre mais de uma razão relacionada com o projeto migratório, assim como que os projetos iniciais que fundamentaram a mobilidade passam por reformulações (MARTINS JUNIOR e DIAS, 2013). Dessa forma, é possível afirmar que os objetivos que orientaram esses brasileiros em migrarem envolveram, muitas vezes, uma combinação de razões e expectativas estabelecidas em relação a diferentes horizontes temporais e espaciais, que são geralmente apreciados no processo de pré-migração.

O projeto migratório constitui, segundo Boyer (2005), o resultado de negociações constantes advindas de diferentes escalas - da rede migratória aos familiares que ficaram na origem, da conjuntura econômica ao grupo social, dentre outros; ao mesmo tempo, também envolve a dimensão subjetiva, que em uma perspectiva individual é resultado de uma construção do sujeito sobre um "porvir migratório", oriundo de suas representações e leituras sobre as realidades do local de destino e de origem.

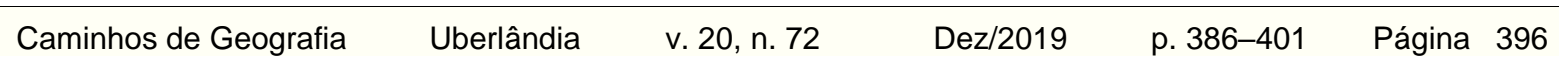


Todavia, é importante ressaltar que os projetos migratórios são fundados dentro dos espaços sociais, espaços de vida nos quais os sujeitos encontram-se inseridos. Nesse contexto, o conceito de campo de possibilidades torna-se importante e nos auxilia no entendimento da maneira pela qual os planos de mobilidade desses brasileiros foram erguidos e traçados ao longo de suas trajetórias de vida. $O$ campo de possibilidade se refere ao conjunto de relações sociais intercambiáveis dos sujeitos com o mundo social, de maneira que não alude somente às dimensões sociais "palpáveis" do lugar, embora as englobe. Trata-se das relações sociais, em sentido mais amplo, que conformam espaçossituações em movimento, maleáveis, que fecham e abrem saídas, conectam e desconectam lugares e pessoas de acordo com as relações entre os sujeitos e o mundo que os cercam. Logo, dependendo da forma como se configuram, as redes de relações sociais, as oportunidades de trocas materiais e simbólicas podem diminuir ou aumentar, e o lugar de vida pode ficar limitado às estruturas sociais locais ou pode ter suas fronteiras ampliadas (TOGNI, 2015).

É sobre esse entrelaçamento entre trajetórias de vida e campos de possibilidades que torna-se importante atentar que os projetos de mobilidade dos sujeitos sempre interagem com outros dentro do campo de possibilidades (VELHO, 2003), não operando em um vácuo, mas sim a partir de paradigmas e premissas culturais compartilhadas em universos específicos. Nesse sentido, é possível considerar que os brasileiros residentes em Lisboa e Los Angeles formularam e implementaram os seus projetos de mobilidades, tendo por finalidade alcançar uma mudança e/ou melhoria na vida, cuja exequibilidade foi dependente das interações com outros planos - as redes sociais, as políticas migratórias do país de destino, as situações financeiras, as relações de afetividades, etc. - dentro de um rol de alternativas que se apresentavam em seus espaços vividos. Ou seja, esses brasileiros agiram para realização de seus projetos e desejos, mobilizando os recursos relacionais e sociais dentro dos campos socioespaciais que estavam inseridos, que thes permitiram concretizar as suas intenções de mobilidades internacionais - cruzar fronteiras.

\section{CONSIDERAÇÕES FINAIS}

Segundo Deleuze e Guattari (apud HAESBAERT e BRUCE, 2009) devemos pensar o desejo como um construtivismo. Nunca desejamos apenas uma coisa: desejamos sempre um conjunto de coisas. Logo, o desejo vem continuamente agenciado. Sob essa perspectiva, os desejos dos imigrantes por migrarem produziram territórios na medida em que esses sujeitos realizaram uma série de agenciamentos no âmbito dos seus campos de possibilidades socioespaciais, que lhes permitiram atravessar as fronteiras desses lugares-territórios dos seus espaços vividos. Essa articulação analítica, que combina condições e processos subjetivos com possibilidades objetivas - ou "campo de possibilidades", contribuiu para ampliar nossa compreensão sobre como e em que condições os projetos desses brasileiros foram gestados e realizados.

Sob essa perspectiva, é possível compreender o migrante não apenas como vítima de fatores conjunturais macro determinantes, mas antes, como sujeitos com desejos singulares e que se inserem na teia de relações sociais. Esta compreensão, por sua vez, possibilita acessar os sentidos construídos por esses entrevistados em suas narrativas de reconstrução do contexto de tomada de decisão da ação de desterritorialização. Assim, a análise das narrativas desses sujeitos brasileiros revelaram que a ideia e o projeto de deixarem um lugar e se mudarem para outro não foi orientada apenas por uma lógica utilitarista de melhoria de vida, mas também foi influenciada por considerações emocionais, como o entusiasmo por descobrir o novo, a realização de um sonho duradouro, etc.

Assim, o reconhecimento dos imigrantes brasileiros como agentes sociais que assumem um papel ativo e forte num processo contínuo de engenharia social dentro dos processos migratórios, exige um olhar sobre a dimensão vivida das experiências de mobilidades dos sujeitos transnacionais. É importante ressaltar essa posição assumida quando se confronta com teorias sobre as migrações internacionais que abordam exclusivamente a racionalidade econômica das intenções e dos projetos migratórios, seja porque consideram a existência de um indivíduo livre e racional, seja porque advogam a existência de uma estrutura social que subjuga o indivíduo:

[...] se o indivíduo não existe nem age de per se, mas só como parte das estruturas sociais, é inexplicável o facto de alguns partirem e outros ficarem [...]. Deverá, portanto, a análise "descer" até às particularidades de certos grupos, tendo em conta a seletividade dos processos e observando alguma margem de manobra (MATOS,1993, p. 18-19).

$\begin{array}{lllll}\text { Caminhos de Geografia } & \text { Uberlândia } & \text { v. 20, n. } 72 & \text { Dez/2019 } & \text { p. 386-401 Página } 398\end{array}$


Ainda, cabe ressaltar a importância de não fixar as análises sobre as mobilidades transnacionais no tempo presente, separadas temporalmente e espacialmente de um passado vivido no lugar de partida, mas sim ampliá-las com a consideração dos relatos dos sujeitos sobre e dos locais de origem. Dessa forma, para o entendimento do significado de "melhoria de vida", ideia recorrente nas narrativas dos sujeitos entrevistados, torna-se imprescindível conjugar as narrativas sobre "o lá" seus locais de origem - e o "cá" - seus locais de destino -, além de reconhecer que, ao longo do processo migratório, os imigrantes produzem e consolidam outras noções para a expressão "melhoria de vida" (MACIEL, 2012). Logo, a análise das narrativas sobre as localidades de origem possibilitou compreender o seu papel importante como ponto de referência (TOGNI, 2015) e de contraste para os sujeitos quando relatam suas experiências do presente.

\section{AGRADECIMENTOS}

A autora agradece o apoio do CNPQ no desenvolvimento deste trabalho, através da concessão de bolsa de pesquisa GDE/CSF 246552/2012-3.

\section{BIBLIOGRAFIA}

ALMEIDA, C. . Fronteira regional no Brasil: o entre-lugar da identidade e do território baianeiros em Minas Gerais. Goiás. Sociedade e cultura, v. 5, n. 1, 2002.

BAILY, S. La cadena migratoria de los italianos a la Argentina. In: BOUCAULT, C E. A.; MALATIAN, T. .(2003). Políticas migratórias: fronteiras dos direitos humanos no século XXI. Rio de Janeiro/São Paulo, Renovar, 1985.

BARDIN, L.. História e teoria. In: Análise de conteúdo. Lisboa. Edições 70, 1997.

BOYER, F. Le projet migratoire des migrants touaregs de la zone de Bankilaré: la pauvreté désavouée. França, Stichproben Vienna Journal of African Studies, v. 8, n. 2, 2005.

BRAGA, F. G. Conexões territoriais e redes migratórias: uma análise dos novos padrões da migração interna e internacional no Brasil. 2011. Tese (Doutorado em Demografia) - Faculdade de Ciências Econômicas, Universidade Federal de Minas Gerais, 2011.

CACHADO, R. D. Á. Trajectos interurbanos na diáspora: o elo esquecido da mobilidade social. Lisboa. SociusWorking Papers, Instituto Universitário de Lisboa,. n. 83, 2009.

CHAMBERS, T. Continuity in Mind: Imagination and migration in India and the Gulf. Cambridge, Modern Asian Studies, p. 1-37, 2018.

CONSTABLE, N. At home but not at home: Filipina narratives of ambivalent returns. [S.I.], Cultural Anthropology, v. 14, n. 2, p. 203-228, 1999. https://doi.org/10.1525/can.1999.14.2.203

CRESSWELL, T. The right to mobility: the production of mobility in the courtroom. [S.I.], Antipode, 38(4), 735-754, 2006. https://doi.org/10.1111//.1467-8330.2006.00474.x

DADALTO, M. C. Imigração e permanência do sonho. São Paulo, Matrizes, v. 7, n. 2, 2013. https://doi.org/10.11606/issn.1982-8160.v7i2p249-263

DA SILVA, J. M. As tecnologias do imaginário. Porto Alegre: Editora Sulina, 2003.

DE ALBUQUERQUE, F. S. et al. Migration in Times of Crisis: Can Entrepreneurship be a Solution? The Case of Brazilian Entrepreneurs in Lisbon (Portugal). [S.I.], Economic and Social Changes: Facts, Trends, Forecast, n. 4, p. 242-258, 2017. https://doi.org/10.15838/esc.2017.4.52.14

DE OLIVEIRA ASSIS, G. Mulheres migrantes no passado e no presente: gênero, redes sociais e migração internacional. Santa Catarina, Estudos Feministas, p. 745-772, 2007. https://doi.org/10.1590/S0104$\underline{026 \times 2007000300015}$

DURHAM, E. R. A caminho da cidade: a vida rural e a migração para São Paulo. São Paulo, Editora Perspectiva, 1973.

FAIST, T. The volume and dynamics of international migration and transnational social spaces. Oxford, Clarendon Press 2000. https://doi.org/10.1093/acprof:oso/9780198293910.001.0001

Caminhos de Geografia $\quad$ Uberlândia $\quad$ v. 20, n. $72 \quad$ Dez/2019 $\quad$ p. 386-401 Página 399


FOUQUET, T. Imaginaires migratoires et expériences multiples de l'altérité: une dialectique actuelle du proche et du lointain. França, Autrepart, n. 1, p. 83-98, 2007. https://doi.org/10.3917/autr.041.0083

GLICK SCHILLER, N.; SALAZAR, N. B. Regimes of mobility across the globe. [S.I.], Journal of ethnic and migration studies, v. 39, n. 2, p. 183-200, 2013. https://doi.org/10.1080/1369183X.2013.723253

GRAW, K.; SCHIELKE, J. S. (Ed.). The global horizon: expectations of migration in Africa and the Middle East. Leuven, Leuven University Press, 2012. https://doi.org/10.2307/j.ctt9afOsg

GURAK, D.; CACES, F. Redes migratorias y la formación de sistemas de migración. Barcelona, Cruzando fronteras. Migraciones en el sistema mundial, p. 75-110, 1998.

HAESBAERT, R. O mito da desterritorialização: do" fim dos territórios" à multiterritorialidade. Rio de Janeiro. Bertrand Brasil, 2004.

BRUCE, G. A desterritorialização na obra de Deleuze e Guattari. Rio de Janeiro, Geographia,

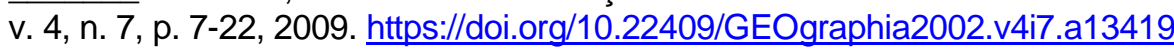

HALL, S. Quem precisa da identidade? In Silva T. T. (Ed.), Identidade e diferença: A perspectiva dos estudos culturais (3.ed.), p.p 103-133. Petrópolis. Vozes, 2004.

KING, R. Theories and typologies of migration: an overview and a primer. - Willy Brandt Series of Working Papers in International Migration and Ethnic Relations 3/12. Malmö Institute for Studies of Migration, Diversity and Welfare, 2012.

LEE, E. S. A Theory of Migration Demography. [S.I.], Demography, v. 3, n1, p. 47-57, 1996. https://doi.org/10.2307/2060063

MACHADO, I. J. R. Imigração brasileira na viragem do século XX: processos de exotização no Porto (Portugal). [S.I.], Ler Historia, n.56, p. 167-182, 2009. https://doi.org/10.4000/lerhistoria.2004

MACIEL, L. M..O sentido de melhorar de vida: arranjos familiares na dinâmica das migrações ruraisurbanas em São Carlos-SP. 2012. Dissertação (Mestrado em Sociologia), _ Instituto de Filosofia e Ciências Humanas, Universidade Estadual de Campinas, 2012.

MAPRIL, Jé. Os sonhos da 'modernidade': migrações globais e consumos entre Lisboa e Dhaka. In A globalização no divã, Lisboa: Tinta da China,2008, p. 65-89.

MARANDOLA JUNIOR., E. ; DAL GALLO, P. M. Ser migrante: implicações territoriais e existenciais da migração. Campinas. Revista Brasileira de Estudos de População. Associação Brasileira de Estudos Populacionais, v. 27, n. 2, p. 407-424, 2010. https://doi.org/10.1590/S0102-30982010000200010

MARGOLIS, M. L. Brasileiros nos Estados Unidos: um estudo sobre imigrantes em Massachusetts. Curitiba, Revista de Administração de Empresas, v. 41, n. 1, p. 88-91, 2001. https://doi.org/10.1590/S0034-75902001000100010

MARTES, A. C.a B. Emigração brasileira: formação de mercados de consumo de produtos brasileiros no exterior. São Paulo, RAE-Revista de Administração de Empresas, p. 8-12. 2001.

MARTINS JUNIOR, A.; DIAS, G. Imigração brasileira contemporânea: discursos e práticas de imigrantes brasileiros em Londres. Lisboa, Análise Social, n. 209, p. 810-832, 2013.

MASSEY, D. S. Economic development and international migration in comparative perspective. [S.I.], The Population and Development Review, p. 383-413, 1988. https://doi.org/10.2307/1972195

et al. Theories of international migration: A review and appraisal. [S.I.], Population Council, p.431-466. 1993. https://doi.org/10.2307/2938462

MATOS, C. Migrações: decisões individuais e estruturas sociais. Lisboa, Socius Working Papers, Instituto Universitário de Lisboa, v. 5, 1993.

MAZZUCATO, V. Transcending the nation. In: Kalb D., Pansters W., Siebers H. (eds) Globalization and Development, Springer, Dordrecht, p. 131-162, 2004. https://doi.org/10.1007/1-4020-2475-4 6

O'REILY, K.; BENSON, M. Lifestyle migration: escaping to goof life? In

Expectations, Aspirations and Experiences, Ashgate, 2009 p. 1-13. Lifestyle Migrations.

PADILLA, B. Integração dos Imigrantes Brasileiros Recém-Chegados na Sociedade Portuguesa: Problemas e Possibilidades. In: MACHADO, I. J. R. Um mar de identidades:aA imigração brasileira em Portugal, São Carlos, Ed. UFSCar, 2006.

\begin{tabular}{|c|c|c|c|c|}
\hline Caminhos de Geografia & Uberlândia & v. 20, n. 72 & Dez/2019 & Página 400 \\
\hline
\end{tabular}


PORTES, A (Ed.). The economic sociology of immigration: Essays on networks, ethnicity, and entrepreneurship. Nova lorque. Russell Sage Foundation, 1995.

RAFFESTIN, C. Por uma geografia do poder.Tradução: Maria Cecília França. São Paulo. Ática, 1993.

SALAZAR, N. B.; JAYARAM, K. (Ed.). Keywords of mobility: Critical engagements. Berghahn Books, 2016. https://doi.org/10.2307/j.ctvpj7jb3

SALES, T. Segunda geração de emigrantes brasileiros nos EUA. Migrações internacionaiscontribuições para políticas. Brasília, CNPD, p. 361-374, 2001.

SANTOS, M. G. C. . Um contributo para pensar a geografia das migrações: a comunidade brasileira na Região Centro de Portugal. 2009. Tese (Doutoramento em Geografia) - Faculdade de Letras, Universidade de Coimbra, 2009.

SAQUET, M. A. Abordagens e concepções de território. Revista Geográfica de América Central, 2007. SCHÖRNER, Ancelmo. Do Faxinal à cidade: migração e desterritorialização-Irati/PR: 1970-1980. Revista de História Regional, v. 15, n. 1, 2010. https://doi.org/10.5212/Rev.Hist.Reg.v.15i1.229257

SILVA, A. V. (2019). Leitura etnogeográfica dos lugares de vida de imigrantes brasileiros em Lisboa e em Los Angeles. 2019 Tese (Doutorado em Geografia) - Instituto de Geografia e Ordenamento do Território, Universidade de Lisboa, 2019.

SIQUEIRA, Sueli. O retorno motivado pela crise na economia norte americana. Tempo e Argumento, v. 1, n. 2, p. 64-79, 2009.

et al. Brasileiros em Portugal e nos Estados Unidos. [S.I.], Mobilidade humana e circularidade de ideia, p. 87. 2017.

TOGNI, P C. A Europa é o Cacém: mobilidades, gênero e sexualidade nos deslocamentos de jovens brasileiros para Portugal. 2015. Tese (Doutoramento em Antropologia). Instituto Universitário de Lisboa, 2015.

TRINDADE, L. S.; LAPLANTINE, F. O que é imaginário. São Paulo: Brasiliense, p. 41, 1997.

TRINDADE, Maria Beatriz Rocha. Sociologia das Migrações. Lisboa. Guide Artes Gráficas, 1995.

TRUZZI, Oswaldo. Redes em processos migratórios. Tempo social, v. 20, n. 1, p. 199-218, 2008. https://doi.org/10.1590/S0103-20702008000100010

TUAN, Yi-Fu. Espaço e lugar: A perspectiva da experiência. Londrina, SciELO-EDUEL, 2013.

VELHO, Gilberto. Projeto e metamorfose: antropologia das sociedades complexas 3.ed.- Rio de Janeiro: Jorge Zahar Ed., 2003.

WEBER, Max. Economia e sociedade: fundamentos da sociologia compreensiva. Brasilia, DF: Editora UNB, 2004.

ZAMBERLAM, Jurandir. O processo migratório no Brasil e os desafios da mobilidade humana na globalização. Porto Alegre, Pallotti, 2004.

ZHOU, M.; PORTES, A. The new second generation: Segmented assimilation and its variants. Reino Unido,The New Immigration. Routledge, p. 99-116. 2012.

Recebido em: 20/12/2018

Aceito para publicação em: 18/09/2019 